\title{
Medical Anthropology: A Review
}

\author{
Veena Bhasin \\ Department of Anthropology, University of Delhi, Delhi 110 007, India
}

KEYWORDS health; illness; healing; social values; social relations; ethno-medicine

\begin{abstract}
Medical anthropology looks at cultural conceptions of the body, health and illness. Medical anthropology is the study of ethno-medicine; explanation of illness and disease; what causes illness; the evaluation of health, illness and cure from both an emic and etic point of view; naturalistic and personalistic explanation, evil eye, magic and sorcery; biocultural and political study of health ecology; types of medical systems; development of systems of medical knowledge and health care and patient-practitioner relationships; political economic studies of health ideologies and integrating alternative medical systems in culturally diverse environments. Ethnomedicine also refers to the study of traditional medical practice. Theoretical classic-Medicine, Magic and Religion defined medicine as a cultural system. In Puerto Rico, spiritism offers a traditional alternative to community health services. Two systems of health care co-exist in Ecuador. Health care in India is charaterised by medical pluralism, including self care, consultations with traditional healers and /or primary health care services (PHCs) These medical systems are complementary, alternative and unconventional. In addition to codified traditional systems- Ayurvedic, Unani and Siddha there is ethno-medicine, religious healing and folk medicine. Indian medical policy is not based on traditional medicine alone. The state health programmes are well intended but lack anthropological consultation. To date, research into traditional medicine has been covered mainly by anthropology and it is suggested that other scientific disciplines should be incorporated in order to further rescue and revalue this part of the cultural heritage that has contributed substantially to human health and to the development of indigenous medical knowledge and its resources.
\end{abstract}

\section{INTRODUCTION}

Medical anthropology can be shortly defined as that branch of anthropological research that deals with the factors that cause, maintain or contribute to disease or illness, and the strategies and practices that different human communities have developed in order to respond to disease and illness (Baer et al., 1997). Medical anthropology is a sub-branch of anthropology that is concerned with the application of anthropological and social science theories and methods to questions about health, illness and healing. Some medical anthropologists are trained primarily in anthropology as their main discipline, while others have studied anthropology after training and working in health or related professions such as medicine, nursing or psychology. Medical anthropologists conduct research in settings as diverse as rural villages and urban hospitals and clinics. Medicine, health and illness are all partly cultural categories and different cultures have their own logic and alternative means to deal with these. Medical anthropology looks at cultural conceptions of the body, health and illness. It also focuses on health behaviour as a way to learn about social values and social relations. Foster and Anderson (1978) ignore the social relations of sickness.
Medical anthropology is the study of ethnomedicine; explanation of illness and disease; what causes illness; the evaluation of health, illness and cure from both an emic and etic point of view; naturalistic and personalistic explanation, evil eye, magic and sorcery; biocultural and political study of health ecology; types of medical systems; development of systems of medical knowledge and health care and patient-practitioner relationships; political economic studies of health ideologies and integrating alternative medical systems in culturally diverse environments.

Ethno medicine is the study of ethnography of health and healing behavior in various societies. Ethnomedicine also refers to the study of traditional medical practice. It encompasses methods of diagnosis and treatment. Ethno medical studies are conducted to evaluate the efficacy of traditional health care practices; the prevalence of illnesses and the distribution of knowledge about illness attributes; the negotiations and instantiation of illness identities; the power of discourse to produce as well as cure affliction; discourse as moral commentary; linkages between medico-religious institutions, models of self, power and the state.

River's (1924) pioneering theoretical classicMedicine, Magic and Religion defined medicine as a cultural system. He perceived medicine, magic 
and religion as "three sets of social processes... so closely interrelated that the disentanglement of each from the rest is difficult or impossible" (Rivers, 1927: 1).During the 1950s many anthropologists were working on problems of international health; they were employed as teachers, researchers and administrators both in universities and in hospitals. This peculiar situation favoured the development of a specific discipline focusing on health and disease (Caudill, 1953). Anthropologists used different methods while writing about health and sickness in respective culture. The earliest anthropologists while explaining about medical beliefs and practices used conceptual systems, which were originally meant for phenomenological domain. The initial work of medical anthropology definition was made possible by the existence of ethnographical studies on rites and religion (Evans-Pritchard's Witchcraft, Oracles and Magic Among the Azande 1937, Turner's Forest of Symbols 1967 and Drums of Affliction 1968, and Spiro's Burmese Supernatural 1967). These studies were best ways to explain medical events in structurally simple, kinship based societies where the people's attention was concentrated on the social and symbolic condition of sickness; by contemporary researchers of culture and personality school in ethnology; by solid roots of physical anthropology; and by the simultaneous action of an international movement for public health (Johnson and Sargent, 1990, Diasio, 1999). In the last three decades, however, a large number of publications focusing on: (1) Medical Ethnographies (Lewis, 1975; Ngubane, 1977; Townsend, 1978; Kimball, 1979; Lindenbaum, 1979; Morsey, 1993; Ohnuki-Tierney, 1981; Young, 1981); (2) Specialised Collections (Lebra, 1976; Leslie, 1976, 1978, 1980; Kleinman, 1978, 1979, 1980, 1981; Spicer, 1977; Ruffini, 1983; Gevitz, 1988) ; (3) Compilation (Loudon, 1976; Grollig and Haley, 1976; Landy, 1977; Logan and Hunt, 1978 ; Morley and Wallis, 1978; Van der Geest and Van der Veen,1979; Kleinman and Lin, 1982; Nichter, 1989, 1992; Romanucci-Ross, 1997); (4) Theoretical Works (Fabrega, 1974; Good, 1977; Kleinman, 1980; Blumenhagen,1980; McElroy and Townsend, 1979; Young, 1981); (5) Text Books (Foster and Anderson, 1978; McElroy and Townsend, 1979; Moore et al., 1980; Murdock, 1980; Wood,1980) have appeared.

\section{Theoretical Explanation of Sickness}

Every culture has its particular explanations for ill health. Frake (1961) during his research among Subanum of Mindanao, explained sickness as a vehicle for pursuing other interests. Like Frake, Good (1977) followed the explanatory model approach. He wrote "illness is fundamentally semantic or meaningful and...... all clinical practice is inherently interpretive......". According to Good, semantic illness network is the network of words, situations, symptoms and feelings which are associated with an illness and give it meaning for the sufferer (Good, 1977: 40). In his analysis of Iranian Semantic Illness networks; Good introduced the notion that networks are organised through core symbolical elements. Good's idea of core symbols closely parallels Turner's notion that there are dominant symbols that organise the meanings of rituals in preindustrial societies. Semantic illness networks are also described in the work of Blumenhagen (1980:198) and Kleinman (1978a, b). Blumenhagen (1980) describes how a population of Americans who suffer from this disease perceives hypertension. Nodes consist of reports of symptoms, interaction, physiological functions, body states, pathogenic agencies and activities. Arrows identify casual relations between nodes. Good's work is different from earlier, more traditional anthropological views of sickness. He thinks that an informant's statements need to be interpreted in the context of his illness experience and close attention needs to be interpreted to the way his statements change over time in-response to his circumstances. According to Good (1977), semantic illness networks are inseparable from the idea that illness is an individualised process. In Kleinman's work, semantic illness networks have been made part of a comprehensive framework (1978 a, b). He classified healing practices of all kinds not so much according to the characteristics of their knowledge basis, but according to how knowledge is transmitted and organised. . Both lay men and health professionals tend to combine their society's individual models of beliefs referred as 'explanatory model' (Kleinman, 1980). Explanatory models provide a structure within which individuals sort out their health problems and understand illnesses, injuries and disabilities. Klienman (1984) grouped healing practices in to three comprehensive sectors: (i) professional sector, which includes both bio- 
medicine and those alternative such as osteopathy and chiropractic which are professionally organised in the United States; (ii) the folk health care sector that includes specialists who are neither professionalised nor bureaucratised; and (iii) the popular sector includes all the things which patient and his relatives do to cure sickness, using their own concepts of what facilitates or delays healing.

Sickness is a blanket term to label events involving disease and/or illness. The anthropologists of sickness premise that social forces and relations infuse medical anthropologist's field. When these social conditions are overlooked or delayed, knowledge of medical proceedings is imprecise. While Kleinman and his associates have been establishing the EM approach, other anthropologists found that social relations which primarily produce the forms and distribution of sickness in society.

Disease-illness scheme by Frankenberg and Young explains that disease retains its original meaning (organic pathologies and abnormalities) and illness refers to how disease and sickness are brought into the individual consciousness. However, sickness is no longer blanket term referring to disease and/or illness. Sickness is redefined as the process through which worrisome behavioural and biological signs, particularly ones originating in disease, are given socially recognisable meanings, i.e. they are made into symptoms and socially significant outcomes. Every culture has rules for translating signs into symptoms for linking symptom-atologies with etiologies and interventions, and for using the evidence provided by intervention to confirm translations and legitimise outcomes (Comaroff, 1982; Lock, 1982; Nichter, 1980). Sickness is a process for socialising disease and illness. In "pluralistic" medical systems, a single set of signs can designate more than one sickness and social forces help to determine which people get which sicknesses. Symbols of healing are simultaneously symbols of power. Specific views of social order are embedded in medical beliefs, where they are often encoded in aetiologies and beliefs about the sources of healing power.

Beyond these roots of medical anthropology, other theoretical areas have deeply influenced its development. All cultures have shared ideas of what makes people sick, what cures them of these ailments and how they can maintain good health through time. This cognitive development is part of the cultural heritage of each population, and from it empirical medical systems have been formed, based on the use of natural resources There has been a strong controversy that should medical anthropologists use the concept of culture or abandon it. The concept of culture exaggerates the distinctiveness, boundedness, homogeneity, coherence and timelessness of a society's way of life (Abu-Lughod, 1991). She implies that descriptions are used in terms of practices, discourses, connections and the events of particular people's life. According to cultural anthropologist Brumann the problems attributed to the culture concept are not inherent in the concept, but are a result of being misused. $\mathrm{He}$ regards culture as a valuable concept for communication and one that is valid as long as we do not exaggerate the degree to which learned concepts, emotions, and practices are shared in a community (Brumann, 1999).

Ecological anthropology, underlying the continuous interaction between culture and the environment, developed a conceptual framework that could be useful in medical anthropology. The theory of evolution, basis of all biological sciences, provided the necessary temporal and evolutional landscape. McElory and Townsend (1977) compiled the first edition at a time when few texts on medical anthropology existed, taking as their framework 'the ecological model and the concepts of medical ecology'. The Fourth Edition of 'Medical Anthropology in Ecological Perspective' (2004) remains very much focused on the medical and ecological, with much discussion of evolution and adaptation-genetic, physiological, cultural and psychological. In spite of fact that the cultural anthropology dominates the text, it remains subservient to this central theoretical approach. Medical anthropologists combine evolutionary theory and field methodology to study the ecology of health. Ecological anthropology, underlying the continuous interaction between culture and the environment, developed a conceptual framework that could be useful in medical anthropology. Medical ecology has provided some key organising principles for medical anthropology. Although no single approach 'unites the field', according to Landy (1983: 186), there is 'broad tacit consensus' that ecology and evolution are core concepts (McElroy and Townsend, 2004: 10).

Some researchers have tried to elucidate peoples' habits as a conceptual framework for 
using a specific medical system or other ways to combat with illness. Habitus is the mechanism that converts objective conditions attached to certain position in the social structure in to subjective aims and motivations in accordance with the principle "to make a virtue of necessity" (Bourdieu, 1980, 1986). The issue of health oriented practices in Bourdieu's work is shown in statistical terms that the amount of time and money which is spent on health caring and body cultivating activities varies significantly between different classes. This connection is interpreted as a manifestation of different relations to the body: 'the way of treating it, caring for it, feeding it, maintaining it reveals the deepest disposition of habitus' (p.190). The habitus theory is eventually a theory of practical sense that explicate the logic and reason of daily practices. Social differences in the role of habits in the health related behaviour are defined as non-reflective, repetitive behaviour. The corresponding theoretical perspective $\mathrm{s}$ is the habitus theory, the theory of individualisation, and the habits as the rational decision rules. Lindbland and Lyttkens (2002) have mentioned three aspects of habits:- the association between habits and preferences; habits as a source of utility; and the relationship between habits and norms. The habitus theory accounts for the logic and reason of everyday practices. The structure of habitus is engendered by practices and directed towards the practical functions.

Roger's (1983) innovation-diffusion model has provided explanation of behavioural changes over time in health promotion research. His analytical focus is on the presumption that there is a social pattern in the process of diffusion, so that higher socio-economic groups lead the way in adopting 'preventive innovations' and lower socio-economic groups subsequently follow as 'late adopters'. This view of diffusion process is akin to the notion of 'imitation social role modeling'. However, the individual choices and judgments are ultimately determined by the conditions of existence, which are bound to the individual's position in the social hierarchy. Through the structure of habitus, objective life chances are transformed to strategies and turned into subjective innovations.

Studies on disability (Edgerton, 1980; Scheer and Groce, 1988; Cunningham, 1989; Groce, 1990) -vision, hearing, speech impairment, mental and physical health problems have argued that though these impairments are universal, the experience of being disabled is largely shaped by the health and social beliefs of the culture in which one lives. In fact, there are several views in regard to disability across the world. They all have explanations for disability, and how individuals with disability are treated and are assigned appropriate roles and responsibilities. These explanations point to the fact that the people with disability have a different status. Many societies have cultural interpretation for disability. Divine displeasure, witchcraft or evil spirits, reincarnation and biology are all given as reasons. The feeling and status of being disabled is shaped by issues of class, gender, family structure, economics, education and regional/ national development.

Studies on mental health and on culturespecific compartmental disorders led to the formulation of the much discussed concept of culture-bound syndrome (McElroy and Townsend, 1989). There are some conditions or specific illnesses, which do not correspond to western diagnostic categories and are restricted to particular area. These diseases have limited distributions around the world due to the fact that unique combinations of environmental circumstances and cultural practices cause them. As these conditions do not fit standard psychiatric diagnosis, these are generally referred as 'culture specific diseases' or 'culture bound syndromes' and can occur among people who share the similar cultural values and beliefs. Some cause relatively minor health problems while others are serious and may prove fatal. For example, Kuru is a fatal culture specific disease of the brain and nervous system that is found among the South Fore, people of the eastern New Guinea Highlands. Hahn (1995) is at variance with the so called "culture-bound syndrome". He contends that culture-bound syndromes are reductionists' explanation for certain complex illness conditions i.e., explanations that reduce complex phenomenon to a single variable. He puts forward that such conditions are like any illness condition; they are not so much peculiar diseases but distinctive local cultural expressions of much more common illness conditions that can be found in any culture (Hahn, 1995).

Interpretive anthropologists have not paid enough attention to larger political, social, economic and historical processes as factors of social class; poverty and power are determinants 
of health status. During last three decades medical anthropology has gained much importance as a field of study, with due thanks to WHO (World Health Organisation). Worsely (1982), Young (1982) and Landy (1983) have compiled excellent introduction to the history and themes of medical anthropology. Numerous research projects and studies have been carried out in which ethno medical, interpretative, critical and/or political economy approaches were applied.

Increasing division in theoretical approaches among the various authors has raised many questions. The important being, whether the facts can be uncovered, empirically discerned, and analysed or they are shaped through interaction between researcher and research subject. Several researchers in medical anthropology made use of empiricist orientation, while many others have focused on negotiation of meaning as key to understanding social life. The means, by which people try to prevent, relieve and heal suffering and disease are formed, transformed and reformed in the field of health. The establishment of therapeutic spaces appears as the product of social and political combinations, of historical speculation, of encounter between people and representations, between ideologies and ideals.

\section{DISEASE PERCEPTION}

Every culture has its particular explanation for ill health. Culture provide people with ways of thinking, that are "simultaneously models of and models for reality" Geertz (1973). Religion has been held responsible for many differences and norms affecting the fundamental values and behavioural pattern in life including health behaviour. Every religion has three aspects: values, symbols and practices. The distinction between natural and supernatural exists in all cultures. Lohmann (2003) argues that a supernaturalistic world-view or cosmology is at the heart of virtually all religions. For him the supernatural is a concept that exits everywhere, even if it is expressed differently in each society. Supernaturalism attributes volition to things that do not have it. On the other hand for Lampe (2003), "supernaturalism" is a problematic and inappropriate term like the term "primitive".

In the western world people usually do not make a distinction between illness and disease. Disease is an objectively measurable category suggesting the condition of the body. By definition, perceptions of illness are highly culture related while disease usually is not. To a great extent, research in medical anthropology, make use of a pragmatic orientation, but a powerful alternative position also prevails, focusing on negotiation of meaning as key to understanding social life.

\section{Causes of Sickness}

In India natural or supernatural forces explain illness. The indigenous theory of tribal of Rajasthan allege that illness results from humoural imbalances stemming from diet, climate, social offences, life activities, astrological and imperceptible forces, spiritual action, witchcraft and sorcery. Accidents, disability, calamity, diseases and losses are readily explained by holding some elements of supernatural or another responsible for. Similarly tribal classify some diseases like colds, fevers and other respiratory infections as illnesses of cold (sardi ki bimariyan); and problems like boils, ulcers, piles, genitorurinary disorders are believed to be illnesses of heat (garmi ki bimariyan). These illnesses are alleged to be caused by excessive internal cold or heat in the body respectively. The cold or heat does not correspond to body temperature but rather to internal humoural state. Sickness is caused by social offences against dead or living or celestial world. Supernatural forces- wrath of gods, goddesses and evil spirits; sorcerers, witches and other agents can also cause illness. In Rajasthan in north India, pox diseases- small pox (Bari Mata), measles (Choti Mata) and chicken pox (Acparo) are attributed to three mother goddesses. The manifestation of pox disease is caused by heat of her presence within the human body. Mata is considered powerful because of her connection with illness especially fever and pox (Bhasin, 2005). The goddess is both feared and esteemed reflecting uncertainty between illness and sacredness. Scientific medicine is believed to have no remedies for these afflictions. People propitiate mother goddess and perform rituals and visit temples. These propitiation rituals are well thought out remedies. It was witnessed that traditional health care practitioners in Rajasthan understand Malaria as 'coldness entering the body', the 'chill disease', 'three days disease' or three fevers in two days, 'dumpling in belly' treat accordingly. The discrimination in each name for the complex illness of malaria, the varying 
time schedule of chill and fever, even the swollen spleen in the last stages, which could be described as 'dumpling' explains their understanding of the disease. In case of diseases like pox, miyadi bukhar (time bound diseases) and motijhara(typhoid), tribal are not concerned about aetiology of the ailment but of development and consequences of it (Bhasin, 2005).

All over the world people believe in Spirits, Evil-eye; Sorcery, and Witchcraft as the root causes of sickness. Evil eye or nazar lagna is one more cause of sickness. This is an illness that afflicts persons who are not very strong or resistant to illness. It is believed that some individuals cast a spell on others just by looking at them. Some do it involuntarily at whosoever comes across their paths; others do it voluntarily because they are jealous of others and desire to possess what others have. These individuals are known to be either very ugly or very beautiful, and when they cast the evil eye, the subject of their envy faces misfortune. The person may fall ill or have an accident. Children are believed to be particularly susceptible to the effects of the evil eye. Omens and dreams are also believed to be harbingers of illness.

\section{By Spirit Intervention}

Tribal theory of sickness describes a different source of evil caused by invisible spirits that exist outside their social boundaries. These spirits inhabit trees, rivers, lakes, mountains and deserted places around the habitation. It is alleged that spirits and ghosts cause various kinds of suffering and are agents of illness and fatality. In India, people believe that angered goddesses, evil spirits, dead persons possess victims and cause distress. Both men and women are possessed, though for different purposes. It is believed that goddesses for good intention possess men, while goddesses and evil spirits possess women for bad purpose.

Possession is a powerful belief system prevalent in many parts of the world. Spirit possession is the concept that gods, demons, or other disincarnate entities may temporarily take control of a human body, resulting in notable change in the behaviour. All spirits are not purely good or evil; the term demonic possession is commonly used is when the spirit is malignant. Unlike demonic possession where the person is thought to be taken over by the devil or his demons for harm, spirit possession is voluntary, culturally sanctioned displacement of personality. The spirits, be they deities, angels, demons or the dead ones are invited to enter a human person. Possession is used to explain unusual occurrences and behaviour. It can also explain the failure of a desired result.

Anthropological studies have been carried out featuring spirit possession (Freed and Freed, 1964; Danforth, 1989; Nabokov, 2000). Freed and Freed (1964) discussed spirit possession as illness in Shanti Nagar, a north Indian village near Delhi. They conceptualised that "spirit possession is like hysteria and is caused due to the individual's intra-psychic tension and a precipitation condition due to an event or situation involving unusual stress or emotion. The basic condition of spirit possession is psychological. Danforth (1989) study presents the religion of Anastenaria religion of Greece and focuses on the worship of the healing power of Saint Constantine. In Northern Greece, the traditions of Anastenaria are upheld through dancing and fire walking, icon worship and spirit possession. Nabokov (2000) presents a Tamil Nadu study of Southern India where individuals worship the healing powers of various Hindu goddesses. The Tamils are a mixed group consisting of mediums who channel the spirits of the goddesses, and victims who are possessed by demons.

In the tribal cultures of India in Bharmour, Himachal Pradesh (Bhasin, 1988), Sikkim (Bhasin,1989), Ladakh, Jammu and Kashmir (Bhasin,1997), and Rajasthan (Bhasin, 2005) spirit possession afflicts both men and women who are in need of healing. Spirit possession becomes an outlet for individuals who suffer from maladies that cannot be cured by modern methods-western medicine, psychiatry or through a judicial system. Among tribal of Sikkim and Ladakh, deities and evil spirits possess men as well as women. The people initially become possessed by being penetrated by the spirit in the form of an illness. The afflicted tribal come to seek the guidance of the ritual specialists (who themselves are possessed by various deities) to know (discover) the cause of persistent illnesses, to resolve personal problems, to be relieved of sorcery spells and possessing demons. Spirit possession is considered a problem to be remedied through the intervention of spiritually possessed ritual specialists. In these areas women are afflicted in large numbers by spirit possession. The 
possessions of women by spirits enable these to cope with physical, mental and social problems. "The relationships between people and the spirits who possess them are thus metaphors for people's social, psychological and physiological conditions (Danforth, 1982: 60). In certain instances, spirit possession is a method by which status quo is maintained. Women gain control over their lives within a male-dominated society through the ritual possession of spirit. Demonic possession is, "a culturally constituted idiom available for women for expressing and managing their personal problems" (Nabokov, 2000: 71). Possession by familial spirits is a common occurrence. These spirits usually possess their relatives at moments when ceremonial protocol at festivals such as marriage, birth ceremonies has been breached.

In the tradition of spirit possession, icons as well as effigies are used to communicate with, and to symbolise good and evil spirits. The exorcists cast their curses upon small effigies of their victims so as to hinder victim's reproductive, vocal or mobile capabilities. Conversely, mediums use effigies to rid people of their demons. In ritual exorcisms, mediums make effigies of the victims, and offer gifts attractive to demons in order to lure them out of the host. Ritual drumming and incantations is a symptom of the trance-like state the spiritually possessed are in. Cultural history of the people and their gods and goddesses; myths or powers of any of the goddesses decide why or how they choose certain individual to become ritual specialists.

The tribal cultures are a part of larger and older traditions that have sought out the healing powers of spirituality. Common people go to spiritual healer for divination and a ritual for healing and pragmatic purposes. Spiritual healing serves as one of the functions of the spirit possession.

\section{Sickness by Human Intervention}

Human intervention is another alleged source of illness. The people believe that diseases can be transferred to other people by crossroad motif. As mentioned above that Evil eye or nazar is considered another cause of sickness. People use the eye metaphor to emphasise evil emanating from envious eye-to eye contact. The science of parapsychology describes the phenomenon as a type of hypnotism, exercising some kind of mind power, which is held by certain individuals.
Causes vary from staring at someone for a long time, showing admiration or envy, gossiping on a person's looks, which can have an effect whether it is negative or positive. Compliments are usually believed to be the cause of the Evil Eye. Common symptoms of the Evil Eye are strong headache, nausea, fatigue or simply a bad mood. According to believers in this superstition, people can only break spells, usually women, who know the right prayers and have been trained to deal with these cases. Practitioners who release victims from the spells pass the prayers on to the next generation. They try to cure the evil eye by amulets and charms or holy water, which they procure from religious practitioners. "Curing the evil eye is, therefore, difficult because it violates the integrity of the human body and creates an orifice that attracts other sorts of evil" (Fadlalla, 2002).

Magic, sorcery, evil eye of Dakan (witch) can cause damage to health, psyche and property. Tribals in Rajasthan believe in evil eye, Dakan (witch), Mooth (zooming through, grains appearing like dazzling) and crossroad motif in disease transference. It demonstrate their belief in magic. People believe that jealousy or 'difference' as important factors for inviting Mooth. Dakan (women with sinister power) activate strange phenomenon like Mooth. It is believed that certain women can instigate spirit of powerful deities or powerful humans to attack on a living soul indicating displeasure of the attacker. These women are regarded as 'Dakan' and are supposed to be in possession of secret evil power, which can be used to instigate malevolent spirit to attack people. These spirits are considered very powerful because they are highly mobile. Sudden illness after returning from forest is attributed to the working of Daken or Bhoot (ghost). Witchcraft is feared even more. Enemies, be they neighbours or relatives, through their own magic or with the help of a sorcerer, can inflict disease and destruction upon others. If the condition remains undiagnosed and untreated, it can lead to death. (Bhasin, 2005).

The belief in spirits as causing sickness, emanating from witches, has also been reported from multi-caste villages (Berreman, 1964; Harper, 1969; Babb, 1975) and in rural areas of Rajasthan (Carstairs, 1985; Lambert, 1992). Comparable observations have been made from other tribal groups of Rajasthan (Bhasin, 2002, 2003, 2004); Sikkim (Bhasin, 1993, 1997); Himachal Pradesh (Bhasin,1990) and Ladakh (Bhasin, 1997). 


\section{Cross-road Motif in Disease Transference}

Diseases are caused or transferred by crossroad motif. By keeping charms on the crossings of four ways, the disease can be transferred to other persons. The charms are kept on the crossings with the belief (i) that it will inflict harm to the person passing by or touching it accidentally; (ii) to appease an evil spirit or deity the alleged cause of sufferance; and (iii) to leave sufferance there. The charms consist of sweets, lighted dough lamps, vermillion, moong daal grains, lemon, coconut, charmol seeds and flesh etc. Doshi (1971) reports that a cross enclosed in a circle is made on the cross roads and lemon slices along with other ingredients are kept on it to inflict sufferance or for transference of disease. Garasias of Rajasthan, in case of child sickness, keep a Rot (a large chapatti) on any of the village crossing to drive illness away.

Crossroad motif in disease transference is common in many countries. Penzer (1968), felt that the 'spot' was particularly efficient in unburdening oneself of diseases and owning probably to its connection with illness and death was a fit place to conjure up evil spirits e.g. Gujrati tribal on the first day of Kartik (November) sweep their houses, collect the refuge in a pot and keep the pot on the cross-roads. It is done with an intention of dispensing evil or passing it on to some travelers.

Amongst the Wagogo of Tanganjika (Africa), the doctor takes his patient to the crossroads along with herbs. He prepares medicine with the herbs and administers a part of the prepared medicine to the patient. He places rest of the medicine under an inverted pot at the road juncture, with a hope that the patient would be relieved of his sickness as someone steps on the pot and get the disease transferred to him. The disease transference motif at the cross-roads in prevalent in people of Japan, Bali, Guatemala, Cochin-China, Bohemia and even England according to Frazer in his 'Golden Bough' (cf. Penzer, 1968).

\section{MEDICAL SYSTEMS}

The health-sickness process is a tangible veracity for all people all over the world. Man has always been concerned about his ailments and he has complex conceptions of life, death, sickness and its treatments. Healers across the world might work on different premise and follow diverse practices however the main goal is to overcome sickness and maintain good health. All cultures have shared ideas of what makes people sick, what cures them of these ailments and how they can maintain good health through time. This cognitive development is part of the cultural heritage of each population, and from it empirical medical systems have been formed, based on the use of natural resources. Both laymen and health professionals tend to combine their society's individual models of beliefs. Explanatory models provide a structure within which individuals sort out their health problems and understand illnesses, injuries and disabilities.

This knowledge of prevention and cure of sickness is passed on from generation to generation. Thousands of years of observation and experimentation have helped in the development of different empirical medical systems around the world, of their conceptions, as well as knowledge of plants, animals, and minerals. Useful elements that have curative potential have been chosen, and taxonomies and different treatments have been developed to address health issues across all societies.

Beliefs about sickness, health and curing comprise a medical system and medical systems are part of the cultural system of any group. Medical systems surface from efforts to combat disease and conquer death, and are social and cultural responses to illness and sick role. Medical systems are the means by which people endeavor prevention, relieve and heal suffering and disease. Medicine is a part of culture and like any other aspect of culture; it has an element of unrecognised inner rationale, and is influenced by non-medical cultural phenomena in number of ways. There is considerable body of literature on health seeking behaviour among primitive societies and folk or peasant cultures (Landy, 1977; Logan and Hunt, 1978). Investigators of illness and healing in different cultures tend to agree that some aspects of health seeking behaviour are universal i.e. client management of alternate systems of curative processes. Treatment strategies employed by the patients or their families on their behalf, range from serial exclusion of one system in preference of another to making decisions that combine elements of several systems. Reliable and comprehensive data on disease level, patterns and trends in tribal areas are required to monitor local epidemics and to 
assess the effectiveness of public health programmes and prevention and control of diseases. In most tribal communities, medical care, treatment and aetiology of disease are defined with in the social context. It is important to identify processes by which tribal recognise sickness and the ways to counteract it. The illness could well be attributed to the evil eye, magic or offending some deity, the treatment for which could be through folk medicine or magico-religious methods. Religious rites are used mainly to treat diseases like small pox and propitiating the deity concerned most of which tribal believe can cure the plagues, which are associated with various diseases. Depending on the nature of the illness, the service of the village priest or medicine man is sought. Illnesses are constructs of belief and knowledge, which vary with time and space. Cultural processes play explicit part in sickness and health. Cultural and biological dimensions of human beings are interrelated. Camaroff (1981, 1983) has warned against treating illness as a "discrete domain of empirical inquiry". Health care/ healing systems/illness constructs "take on meaning in context, not as bounded set of activities, imposed categories or stock responses to objectified form of misfortune. An analysis of illness and idioms of distress, form of conflict resolution, and modes of therapeutic transformation demands a multidimensional assessment sensitive to coexisting health ideologies and shifts in social relations associated with modes of production, form of technology, and availability and distribution of resources, changes and population dynamics, etc." (Nichter, 1992). Unreflective empiricism applied to the study of health, illness and healing is ethnocentric, yielding "disembodied classifications of terms, whose meanings remain nominal, telling us nothing of their pragmatic use, their polysemic quality, their cultural significance" (Camaroff, 1983: 9).

Medical systems are an integral part of all cultures, which affect the health status of the people. The medical system includes the totality of health knowledge, beliefs, skills and practices of the every group. It includes all clinical and non-clinical activities, the formal and informal institutions, and other activities that are even remotely connected with ill health of the community. Environmental sanitation and nutritional education and scientific knowledge underlying these activities are just as much part of the medical system as the physician's practice. Every culture has developed a system of medicine, which stand an enduring and shared relationship to the existing worldview. The medical behaviour of individuals and groups is understandable discretely from common cultural history. Historical and political conditions have paved the way for contemporary therapeutic spaces and how these have been identified and legitimised.

The medical systems of all groups, however simple some may be, can be divided into two major categories: (i) disease theory system, and (ii) a health care system.

A disease theory system embraces beliefs about the nature of health, the cause of illness, and the remedies and the other curing techniques used by doctors. In contrast, a health care system concern with ways employed by the society to deal with sickness and maintenance of health. The knowledge of disease theory and health care system of a society enables us to cope more wisely, more sensitively while introducing new medical system among people who have known traditional system previously. Traditional disease causation ideas often persist long after western innovations in health care have been introduced.

Basically, there are two systems of health care in the developing world: one is traditional and the other is Western in derivation. The concept of traditional medicine is a conventional term used by medical scientists to refer to the empirical medical systems used in different cultures all over the world. Each society has its own worldview of origin, causes, concepts, practical therapies of sickness and has also developed the specialists that know how to apply them. Traditional medicine include all kinds of folk medicine, unconventional medicine and indeed any kind of therapeutic method that had been handed down by the tradition of a community or ethnic group. It is customary to find all kinds of practices grouped under the common heading 'traditional medicines'- mainly because they do not emanate from the biomedical paradigm. The medical traditions in the traditional system are diverse in their historical background, theoretical logic and practices, their contemporary social realities and their dynamics. By the World Health Organisation (WHO, 1976) definition, traditional medicine is the sum total of all knowledge and practices, whether explicable or not, used in diagnosis, prevention and elimination of physical, mental or social imbalance and relying exclusively on practical experience and observations handed 
down from generation to generation, whether verbally or in writing. With these descriptions, various forms of medicines and therapies such as herbal medicine, massage, homeopathy, mud bath, music therapy, wax bath, reflexology, dance therapy, hydrotherapy, mind and spirit therapies, self-exercise therapies radiation and vibration, osteopathy, chiropractics (a system of complementary medicine based on the diagnosis and manipulative treatment of misalignments of the joint, especially those of the spinal column), aromatherapy, preventive medicine, radiant heat therapy, therapeutic fasting and dieting spinal manipulation, psychotherapy, etc. are a few elements of traditional medicine. It does show that a large country like India, with diverse cultures and traditions, should be rich in traditional medicine.

In the traditional medical systems, medical traditions partly cover other sectors of social life. The beliefs and practices of health, knowledge and its transmission, refers as much to the religions and the therapeutics, as to the economic, and the political fields. It forms a coherent whole, the object of which is to explain, to prevent, to relieve or heal what stems from misfortunes and cause illness. Traditional medical systems therefore cannot be studied exceptionally.

In contrast to traditional health care system, the official health care system is based on Western science and technology. In keeping with the scientific tradition, its practitioners make every effort to separate themselves from broader social and cultural concerns and influences. Though scientific medicine has its roots in traditional practice, its practitioners are "rather embarrassed" by it (Vaskilampi and MacCormac 1982: v). Western medicine has influenced large regions outside the west markedly in Asian countries. Leslie (1976) identified these systems as "cosmopolitan" whereas Worsley (1982) referred to these systems as "Western" because it does signify the origins of the system.

The folk aetiology of diseases is forever in consonance with the socio-cultural conditions of the area. Comparative studies of cultural illnesses and healing techniques guided by either a search for universalism or cultural relativism have been carried out. Traditional medical traditions have continued to co-exist with biomedicine. The term "Traditional Medicine" or "Traditional Systems of Health Care", refers to long standing indigenous systems of health care found in developing countries and among indigenous populations. These traditional medical systems view humanity as being intimately linked with the wider dimension of nature .The World Health Organisation has referred to these systems as "holistic"-i.e., "that of viewing man in his totality within a wide ecological spectrum, and of emphasising the view that ill health or disease is brought about by an imbalance, or disequilibrium of man in his total ecological system and not only by the causative agents and pathogenic evolution". The treatment strategies used in traditional systems of health include the use of herbal medicines, mind/body approaches such as meditation, and physical therapies including massage, acupuncture and exercise programmes. These are low-cost, locally available treatments, which according to WHO are utilised as the source of primary health care by $80 \%$ of the world's population. At present, more than 20 centers around the world collaborate in the WHO Traditional Medical Programme.

In the traditional medical systems the knowledge of health and illnesses is not codified, but is widely shared between users and practitioners (Press, 1978: 72). Traditional medical systems enunciate theories of disease aetiology and arbitration within a larger cultural framework of moral, ethical, religious, and supernatural concerns. The underlying causes of illnesses are generally seen as some kind of imbalance or lack of harmony in the body, the social environment, the spiritual world or the cosmos. Religious and charismatic healing belongs to the folk medical system because therapy is affected by means of prayers to, and faith in a supernatural being. A relatively modern term, folk medicine has come to mean the care of the sick by unlicensed healers, including those who practice herbal and magical medicine. The traditional health system in India comprises of two social streams - local health beliefs and practices relying on instantaneously available local resources; and the codified organised knowledge based on theoretical foundations (Ayurvedic, Siddha and Unani). Traditional folk practitioners include: herbalists, bonesetters, traditional birth attendants, spiritual healers and other specialist.

Ethnic medical literature has defined two types of Traditional Health Systems-the naturalistic system and personalistic system. The naturalistic systems have been described as those, which are natural sciences with 
controlled investigation of documented materia medica having a comprehensive theoretical framework against which treatments are tested and new treatments are generated. The personalistic traditions have been described as these which have the knowledge of healing, possessed by an individual either selected by someone in the community or by a process of divine revelation, or by revelation of some form.

The state-supported western medical system. which tends to be synonymous with a monopolistic medical "establishment" and a doctor-dependent, hospital-based, curative health care model, does not generally recognise, cooperate with, or adjust to the traditional medical systems (Good et al, 1979). The two exist side by side; yet remain functionally unrelated in any organisational sense. There is the belief that with the recognition of traditional medicine and the political commitment to humanistic health care reform, better use of scarce resources for the common good can be made. Techniques and medications of modern practice are increasingly filtering down to local healers. Folk, popular and orthodox medical practices may coexist, compete and intermingle with one another within a single community, nation or region. Indeed, many traditional or popular health beliefs may be supported, reinforced or rejected by biomedical explanations. The combined use of both types of expertise provides an optimal broad-spectrum response to health problems. "Medical pluralism offers a variety of treatment options that health seekers may choose to utilise exclusively, successively, or simultaneously" (Stoner, 1986: 46). People may try a variety of practitioners and treatments, from the same or different systems, until a cure results. In many societies the continuing process of negotiation takes place as patients seek therapies and aetiologies consistent with their understandings of illness (Morsy, 1993). Patients may accept some aspects of the scientific health care system as presented to them by a government physician, and they may supplement this with information gathered in consultation with traditional healers. The systems differ in availability, quality of care, levels of technology, and social adaptability; yet, ideally, both are intended to serve the same population in need.

In colonial times, authorities frequently outlawed traditional medical systems. In postcolonial times the attitudes of bio-medical practitioners and government officials have maintained the marginal status of the traditional health care providers despite being the fact that among rural people in the developing countries the traditional medicine serves an important function. Organisational relationship between modern and traditional medicine can come about in four different ways-monopolistic, tolerant, parallel and integrated. Factors influencing the status of traditional medicine in policy making are economic, cultural, national crisis (war and epidemics) and international pressure to conserve traditional knowledge, which will otherwise disappear because of lack of documentation. Indian Medical Council Act formally established the Traditional Systems-Ayurvedic, Unani and Siddha-as officially components of national health care in India. In Ladakh, a traditional medical system Amchi has been incorporated into health planning. It is based on Tibetan medical system, and is holistic, cost effective and locally available (Bhasin, 1997). The relationship between folk and classical traditions in India is symbiotic. There is strong similarity in underlying theory and worldview expressed at the level of theory of causation of some diseases. There is also a striking common ground for technical terms that are used by folk-healers and traditional practitioners such as vaata, pittaa, vaayu, kapha, ushna, sheetala. All these terms form part o the knowledge of folk practitioners and the households. The classical text of Ayurveda also mention about the folk traditions and healers. In Charaka Samitha, it is mentioned that " goat herds, shepherds, cowherds and other forest dwellers possess knowledge about herbs and its use in sickness"'(shaloka-120121). Likewise it is mentioned in Surutha-Samhita that "one can know about the drugs from the tapasvis (an ascetic), hunters, those who live in the forest and those who live by eating roots and tubers" (Chapter-36, shaloka).

Traditional or local medicine still remains an important source of medical care in the developing countries even though it is not officially recognised by the government health care programs (Jaspan, 1969; Kleinman, 1980). It persists in urban as well as rural settings despite the availability of allopathic health services. Studies have shown, however, that its general persistence is decreasing in importance over generations, particularly among socially isolated nuclear families. In traditional medical systems worldwide, afflictions that beset body and mind can be explained in both naturalistic and super 
naturalistic terms. When a wound does not heal, when a sickness does not respond to treatment, and when the normally expected and predictable does not happen, other explanations beyond the organic are sought (Hughes, 1978). The rise in status of folk healing systems in capitalistic countries is contingent upon gaining "acceptance from strategic elites who are seeking solutions to the contradictions of capitalisticintensive medicine and/or by patients who demand forms of treatment neglected by orthodox medicine." (Baer, 1984: 3).

\section{ANon-Medical Approach-Faith Healing}

The widespread popularity of religious and non-medical faith healers bears witness to the fact that people have deep-seated faith in cures brought through faith healing. Such people attribute supernatural causes to disease and for them it is important to know whether a particular disease in a patient is due to the wrath of a goddess, the work of an evil spirit, sorcery, witchcraft, or the breach of a taboo. Once this has been found out, obtaining a cure is a matter of following the advice given by a faith healer.

The art of healing practiced in all the ancient civilisations - Indian, Chinese, Mesopotamian, or Egyptian - in a large measure, was based on the belief that diseases were caused by different supernatural agencies. Patients as well as their relatives have complete faith in the competence and skill of the medicine man to cure these diseases by means of his supernatural powers. In India, as far back as the days of the Atharva Veda, people believed in the wrath of gods, the mischief of evil spirits, and the magic of human beings. Faith healing is still practiced in villages, tribal areas, and even in cities. In Ladakh, people's dependence and confidence on traditional medical practitioners (amchi) and faith healers (lhama/lhapa) is the result of faith and self-belief of the patients.

Even though healers may adopt different methods, they follow a common working pattern. They identify the name of the illness and its probable causes. This wins over the patient's trust. The patient develops a rapport with the healer and believes he can cure him. The healer's reputation, the aura created around him, and the equipment he uses - all add to win over the subject's confidence. A suitable method of healing is selected, keeping the subject's background and symptoms in mind.
Just as a practitioner of allopathy begins with the history of present illness, so does the medicine man start by interrogation. He questions the patient in order to find out whether he has intentionally or otherwise broken a taboo; has been disrespectful to a deity; has not cared or provided for an ancestral spirit; if he has noticed any strange object in the surroundings; has had a quarrel recently with a neighbor, or relative; or if he suspects somebody intends him harm or illness. The medicine man asks the patient about his dreams; he interrogates other family members to find out what they think about the probable cause of the illness; he looks for omens. The role that faith plays in bringing about relief or cure is witnessed by practitioners of every system of medicine. Emotions and attitudes raised by a physician have a tremendous effect upon the patient. Some doctors are said to possess a 'healing touch'. A large part of this healing touch depends upon the doctor's personality and manner of eliciting the faith of the patient. The role of faith in a particular person - be it a priest or a fakir - and his blessings or medicaments in the cure of a patient, even though the latter may be suffering from a seemingly incurable disease, cannot be denied.

\section{TYPES OF TREATMENT}

In most systems of healing, the treatment of a disease is decided after identifying the cause of that disease. If an educated man believes that the cause of malaria is the malarial parasite that reaches the bloodstream through the bite of an infected mosquito, then to get a cure he takes chloroquine or an allied drug, and to prevent further attacks, he tries to keep mosquitoes away. In a similar fashion, those who believe the cause of the disease to be the wrath of a god, influence of an evil spirit, sorcery, or breach of a taboo treat that disease with such measures as are appropriate for its cure and prevention.

After the medicine man or medical technician has identified the cause of the illness, he requests the different spirits by name to reveal them and to indicate their demand. He requests his helping spirit in the other world to find out the truth and reveal it to him, which the latter does either directly to him, or by entering the medicine man when he is in a trance and speaking through his mouth.

It is indeed remarkable how often patients 
benefit from this divination. Some get instantly well after a competent healer has diagnosed their case and advised the appropriate offerings. There are, of course, cases where the diviner fails. Then other means of cure are adopted. In the case of wrathful gods and goddesses, propitiation is done through religious prayer, incantations, and offering animal sacrifices. In the case of evil spirits of various types, different measures are adopted which include propitiation, driving away the evil spirit, and exorcism. Some healers believe in touch as the cure: laying-on of hands on the inflicted person or touching his aura or energy field. Other healers propitiate gods and goddesses by exorcism, rituals, sacrifices or incantations.

\section{Types of Treatment Methods}

1. Traditional medicine alone;

2. Traditional medicine in combination with spiritual healing;

3. Spiritual healing alone (exorcism is used in spiritual healing, apparently to cast away the evil spirits causing disease);

4. Other forms of alternative medicine; and

5. Western or biomedicine.

\section{Traditional Healer}

The traditional healer is an expert in curing diseases with out having basic knowledge of disease causation and treatment. However, he shares the knowledge of disease, which is pertinent to that particular culture. He understands the concepts of illness and knows all about causation and origin of disease as rest of the members of the society comprehend. The traditional healer, as defined by the WHO (1976), is a person who is recognised by the community in which he lives as competent to provide health care by using vegetable, animal and mineral substances and certain other methods based on the social, cultural and religious background, as well as on the knowledge, attributes and beliefs that are prevalent in the community, regarding physical, mental and social well-being and the causation of disease and disability. The use and practice of this knowledge is a responsibility that implies socially recognised and legitimised power. The traditional healer has a specific name in each culture, has the authority and respect of his community for his commitment to maintain the well being of everybody. The concept of "person" is at the core of the traditional Cosmo vision. This unites the perceptions and functions of the physical body with the concept of subjective entities that encourages it, give it strength, vigor and resistance. Under colonialism, our culture suffered conceptual losses due to the clash of different visions of the cosmos. With the advent of modernisation, new techniques and natural resources from other parts of the world were brought and incorporated according to necessities. As a resource for health care; traditional medicine still benefits ethnic groups and rural, urban and popular cultures in our country. As an alternative practice to official medicine, it retains its effectiveness and social legitimacy for large number of people.

In every culture there are specific social subjects that are chosen for their sacred and profane characteristics. Through the transmission of the tradition, all populations obtain the sum of the knowledge of cures and procedures that are based on their own worldview. In this fashion, the traditional healers in each society synthesise the ideology, the diagnosis and the therapies. Along with, the properties of natural elements, herbs and vegetation to be used for therapeutics are also learned. They are not only skilled at the collection and treatment of plants and other organic material that have best curative qualities but are also trained to know the myths of creation of all, cultural projections and representations; the exact pace of keeping harmonious existence of man-nature-universe and its symbolic and transcendent relationship with the sacred. The acquiring of this knowledge has its own rules and prohibitions, its efforts and tests, and requires guidance from another specialist, knowledge of sources from direct experience and also internal reflection to express the logic of its classification of the sacred or profane world. Knowledge of the available resources was socialised by cultures as a means of survival and social reproduction.

\section{Types of Traditional Healers}

Specialists in Home Remedies: the 'specialists' in home remedies are elder people who do not consider themselves healers, but suggest and give plant remedies in case of illness.

Herbal Specialists: Who treat people with the help of herbs available in the vicinity. They learn the secrets of the trade from their fathers or any other expert in the required field; 
Ritual Specialists and Spiritual Healers: Who treat with divination and therapeutic cult rituals. The therapeutic rituals as practiced by ritual experts and lay persons tend to focus on symbolically encouraging and assisting the putatively natural course of the sickness or on transferring it away from the patient's body, rather than on 'treatment' or 'cure' in specific sense. Spirit possession religions and popular rituals flourish in tribal areas. Most of the popular sects and shamans involve varieties of rituals and medium ship. One of the largest and most widespread of the belief systems is the spirit possession ritual, where spirit mediums channel various gods and goddesses connected to the cult. The ritual specialist enters a trance before becoming possessed by the spirit. The possession usually occurs during religious ceremonies and only lasts during the event. During voluntary possession the mediums don specific apparel, which facilitates manifestation of the spirit in their bodies. Certain rituals accompanied by incantations of verses are performed to invoke the tutelary spirit, which will ultimately possess the ritual specialist. Many believe that during possession, goddess speaks and heals through the healer.

The spirit possession and going in to trance ritual, despite it's outwardly trappings, is generally sought out by petitioners to achieve down to earth goals:-curing of sickness and other miseries. Trance-like state is indicative of spiritual possession. The cure involves the intercession of a spirit that has the power to expel the offending demon. The spirits use medium as vessel to help victims with their problems caused by demons. Likewise, the victims become vessels for communications for the demons. It is during exorcisms that the victims would enter a trancelike state, and channel the voice of the demons. The supernatural powers are channelised through human hosts. Tribal of Bharmour, Sikkim and Ladakh believe that in cases of possession the cure is not accomplished by the Shaman(Hindu chela among Gaddis of Bharmour, Himachal Pradesh; Buddhist bongthing and pau among Lepchas and Bhutias of Sikkim; Ihama/ lhapa among Bodhs of Ladakh and bhopa among the tribal of Rajasthan). However these merely act as vehicle of treatment. The shaman enables the divine spirit to come in contact with the spirit, or dijn affecting the hapless victim. The shaman facilitates the encounter. Thus during the encounter the exorcist and the victim are very much alike-they are both simultaneously possessed by an alien spirit. However, there is one important difference. The patient was disinclined and taken unaware during his sleep, while attending a funeral or walking under a haunted tree or any such place. On the contrary, the shaman by virtue of his training and qualifications is in a deeper consciousness and heightened state of awareness and is not as much of the victim of the possession. His possession is voluntary and thus a participant in the spirit world. By vehemently entering this expanded state, the shaman is able to exercise a limited control over the spirit. Thus, while it is the spirit and simply spirits that can affect cure, the shaman by virtue of his ability to interact with both the world of the spirits and world of man is able to direct the consideration of spirit toward the suffering and sickness caused by possession. Possession is cured by contact with a more powerful spirits, not by expansion of consciousness from within; and

Magico-religious Healer: Who treat illness believed to be caused by supernatural forces. $\mathrm{He}$ exorcises evil spirits and suggests preventive measures against the attack of evil spirits. Charms and Amulets are also recommended.

By far the most potent method of driving out spirits is exorcism - the expelling of evil spirits through the magic power of the word. Certain words have to be chanted at the right moment if the spirit is to yield to mechanical pressure or let it be transferred. These incantations can take the form of commands, such as ordering the spirit to relinquish its host, or appealing to more powerful spirits for intercession. Spells can be cast: that is, words are combined in such a way that on hearing them a spirit cannot resist them. The ritual of exorcism takes different forms among different people in India.

Preventive measures against the attack of evil spirits are also taken. Evil spirits are believed to shun certain colors, metals, or fumes; hence, these substances are used widely to keep evil spirits away. Since spirits are believed to avoid black, red, and yellow colors, vermilion is commonly used; they avoid iron, hence, articles made of iron are kept under the head while going to sleep. Mauli (red and yellow thread) is tied around patient's wrist and it signifies that any spirit which dares to come near will be tied up with it; leaves of certain trees are hung about the door for the 
same purpose; ghee and asafetida are sprinkled around the house, and certain figures made of mud or metal are commonly hung near the entrance of the houses. Among Buddhists, the practice of raising prayer flags and constructing prayer water-wheels is widespread. In Ladakh, chan, specific kind of paintings with bright and striking colours are made on the outer surface of the walls of the houses as preventive measures. These chan are redone periodically. People hang skull of a goat on the outer wall of the house, framed in small sticks tied together by a twine which is torma obtained at the Losar festival. These are hanged as insurance against sickness. The corners of the houses are painted red, which successfully bars the admission of the evil spirits.

There are curing ceremonies in which effigies are destroyed: the effigies can be personification of the disease demon or even a representation of an individual who is believed to have infected the donor of the ceremony with some disease. In some areas, during Losar (New Year) festival Ladakhis celebrate Dosmoche , the great festival of scape goat. Torma (effigies made in various sizes to represent men and demons. Tormas are replacements for human sacrifice which was offered to the gods and demons in pre-Buddhist time)are carried in procession to open area where a huge creation made of sticks, tied together by threads has already been prepared. At a given moment all torma are thrown into flames and with their burning, the sins and diseases of the place are consumed. After this the erection of the twigs is knocked over and every man makes a mad rush to obtain even a small piece if he can, which is carried home and placed on one of the outer wall of the house, thus protecting its inmates from disease and death. Sikkimese Buddhists also employ complicated mast like structures consisting of sticks, threads and tuffs of wool. These structures are known as thread crosses and act as contraptions for catching demons. These contraptions are renewed and the old ones are destroyed after they have served the purpose for which they were erected or when they become saturated over time with evil spirits (Bhasin, 1990).

\section{Charms and Amulets}

Charms and incantations are also used to bring about cures of different diseases. In the tribes of Himalayas, once the cause of the disease is decided, the patient will consult the practitioner accordingly. However, before starting the treatment one may tie charmed amulet for one cannot be always certain of a physical aetiology of the illness. An amulet is an object worn or carried on the person, or preserved in some other way, for magico-religious reasons, that is, to cure disease, provide luck, or protect the possessor from specified danger or misfortune. Tying a charmed amulet is common preliminary act which serves two purposes: (i) if the disease is caused by external agents, then the amulet may cure the disease. The charm also protects the individual against the demonic interference. The efficacy of the amulet is generally for a limited period. If disease is not cured a bigger ritual may be require; (ii) an amulet may act as a protection even if the cause is physical manifestation, for spirits can attack a person in a physically weak state. In some villages in Punjab, aches and pains are treated by madaries (charmers). Enchanted ashes are rubbed on the affected part of the body, or enchanted water or other edibles are given to the patient. Enchanted threads are tied round the leg, neck, arm, or waist as a cure for aches and pains.

A favorite mode of using charms is to write the formula on paper or on the inside of a cup, and then to dissolve the writing in water, which is administered to the patient. Charms are also engraved inside metal cups, which are reserved for this special purpose.

The most popular charm against the evil eye is kajal or lamp black, which is smeared around the eyes of a child. But if in spite of the above precaution a child is exposed to the evil eye, the mother takes the dust from the footsteps of the person who is responsible for having cast an evil eye on it. The dust is roasted over a fire and then thrown away.

A majority of children in the tribal areas are seen wearing amulets around their necks or loins; some of them possess about half a dozen amulets, each one for a particular purpose. Men and women wear them on their person in the form of necklaces, girdles, bracelets, anklets, or pendants. The material of which the amulets are made depends upon different factors, one of which is the availability of a particular material in the area. Some natural and artificial objects used as amulets are stones, especially those of a curious shape or naturally perforated; curious vegetable growth, roots, leaves, seeds, nuts; horns, teeth, claws and other parts of animals and insects; shells; human hair and teeth, relics of the dead; medicinal 
substances, substances believed to have been extracted from the sick in magical cures; iron, gold, silver, rock crystal, alum, salt, coral, strings, threads and rings; representations of eyes, hands, horns and crescents; beads, written charms, quotations from sacred writings, inscribed objects, medals, coins, obsolete weapons and ornaments; relics and momentous of holy persons and places; portions of offerings and dedicated objects.

Vaids: In India, another group of specialists are Ayuevedic/Unani/Siddha doctors or vaids. The vaids are the practitioners of the indigenous system of medicine with a well developed theoretical basis, in tune with the social, cultural and philosophical traditions of the time when it flourished in India.

Medical Doctors: These are degree holders from recognised institutes/universities and are practitioners of allopathic system of medicine.

\section{MEDICAL PLURALISM}

Medical pluralism may be defined as the synchronic existence in a society of more than one medicine systems grounded in different principles or based on different worldviews. In Puerto Rico, spiritism offers a traditional alternative to community health services. Practitioners of 'espiritsmo' the major traditional healing system in Puerto Rico are mediums that can exorcise illness-causing spirits and assist clients to acquire enlightened spirit guides and protectors.

In Latin America, particularly in the Andean countries, there is interdependency of medical systems. In a culturally diverse and socially stratified population of Latin America, medical systems constitutes a social representation resulting from the historical relationships between autochthonous medical cultures and those from other latitudes. "The impregnation of scientific and popular knowledge results not only in the incorporation (and often expropriation) of folk in professional or scientific medicine, but also in the increasing 'medicalisation' of popular medicine and traditional therapeutic practices" (Pedersen and Barriffati, 1989). The degree of competitiveness, co-operation or integration among medical systems depends mainly on asymmetrical distribution of power and resources, and is conditioned by he population's behaviour in the management of disease.
Ortega (1988) reports that two systems of health care co-exist in Ecuador. The traditional system combines elements of the indigenous system, the modifications brought by the Incas, and elements of Medieval European medical theory and practice. The official medical system comprising both public and private institutions is inaccessible for large sections of population due shortages of manpower and materials and high cost of services.

In Guatemalan, the symptoms are treated with modem medicine, while the cause of illness is dealt with through a folk specialist, Gonzales (1966). Traditional or folk theories of illness aetiology are often multifactorial and multilevel (e.g. immediate and ultimate levels of causation), which permits the use of different treatment resources for the different causal factors and levels (Cosminsky, 1977).

In most parts of India, multiple therapy systems and a diversity of health behaviour patterns co-exist. Health care in India is charaterised by medical pluralism, including self care, consultations with traditional healers and /or primary health care services (PHCs) These medical systems are complementary, alternative and unconventional. The status, growth and evaluation of co-existing therapy systems are influenced of by cultural ideology, ecology, political patronage and changing social institutions. India, like other traditional societies has a wealth of medical knowledge. In addition to codified traditional systems-Ayurvedic, Unani and Siddha there is ethno-medicine, religious healing and folk medicine. Apart from these there are ritual cure specialists (shaman), known by various names, who treat culture-bound syndromes. Besides, every household knows how to treat simple problems with the plants available in their backyards or spices from their kitchens. The pluralistic medical situation of doctors and deities in tribal areas provide flexibility and fulfills different needs of the community. The folk systems are open as manifested by eclecticism of both the clients and practitioners, who adopt and adapt from an array of co-existing medical traditions. This openness of folk systems, as Press (1978) point out, is manifested by the acceptance of inputs from other/alternative health systems, and also inputs from institutional sectors such as religion and family. According to Landy (1974) the traditional healer role stands at the interstices religion, magic and social system and 
gain its power from this position. This contrasts sharply with the closeness of biomedicine, which is "discontinuous from ordinary social processes" (Press, 1978; Manning and Fabrega, 1973) and is unaccommodating to alternative systems.

Khare (1996) in his paper explicates 'practiced medicine' in India and "how India manages not only multiple traditional and modern medical approaches, languages, therapeutic regimens and material medica, but it also leads us to a sustained moral, social and material criticism from within. The study of such diversity leads to a loosely shared, and ethnographically attestable, cultural reasoning, practice and practical ethos across the traditional and modern medical worlds"(ibid).

The Ladakhi's response to problems of health and disease has components from various systems of medicine. Components of Ladakhi medical pluralism are Lamaism, Shamanism (locally known as Ihawaism), scholarly Amchi medicine and allopathy. The religious background, particularly the belief in fear of evil spirits, the influence of Shamanism, healing performed according to Bon rites, means of protecting against evil spirits, amulets, thread crosses etc., make Ladakhi medicine colourful and multifarious. The plurality enables them to switch from one type of health practitioner to another in search of the best. The Ladakhi who can avail the facility of western or bio-medicine does so without being familiar with the theoretical principles of medical system. Although the economic statuses of the households differ, they show certain similar patterns of illness behaviour. They employ pluralistic strategies not perceiving conflict among these alternatives, nor do they seem to perceive them as different systems, but rather as a variety of options, among which they can choose.

Most usage is sequential but some is simultaneous. For example, an infant who is being given prescribed medicine for diarrhoea, may also be taken concurrently to a Lama for the evil eye. Although certain illnesses such as evil eye are thought to be cured only by folk curers, this does not preclude the use of modern medicine to treat the symptoms. As reported by Cosminsky (1980) for Guatemalan plantation, pluarlistic behaviour among Ladakhi population groups is pragmatic, often based on trial and error, perceived effectiveness, uncertainty of illness causation and expection of quick results. In addition to this empirical and pragmatic behaviour, however, is the role played by faith in the supernatural or spiritual in curing. As a person is simultaneously a body (his soma), a self (his psyche) and a social being (his polis), so are healers corresponding to three different realms of individual functioning. In other words, a person is simultaneously a body, a self and a social being. Ladakhi Shamanism "pursued a dialogic, relational remedy for its patients through reciprocal relationships that encouraged community, such as in gift giving to spirits and etiologies based on real social conflicts" (Adams, 1992: 154). Ladakhi shaman attempts to resolve sickness caused by disorder of the "Social self". Lamas and Amchis on the other hand claim to cure the diseases which arise from disorders of body and mind and are originating from individual actions and desires in craving and clinging. Excessive anger, greed and lack of discipline in attachment to the physical and social world result in body disorders.

Lamas cure with prayers and rituals while Amchis cure through the site of the physical body by means of an elaborate diagnostic system and pharamacopeia. Bio-medical systems as a rule stand in sharp contrast to the indigenous ones, although a study done in Kerala and Punjab has suggested that there are numerous indigenous medical practitioners who used western medicine, including penicillin injections (Neumann, 1971: 140-141). Among Ladakhis, no such practioners exist as Lhamal/Lhapa are spiritual healers and Amchis are traditional herbal doctors, who do not use biomedicine.

Indian medical policy is not based on traditional medicine alone. It is comprehensively pluralist, since biomedicine, in all its forms, from hospital based surgery to health centres to dispensaries is being fully utilised. The integration of the two systems is conceptual. These systems just co-exist, side-by-side. Common people around the world assume that only their medical systems can actually cure. Curing with any medical system may work because of three different factors. First, a cure may be successful because the medical procedures actually help the patient recover from illness. Second is faith healing i.e. the faith of patient in the healer. The third reason that a cure may work is because of placebo effect.

Traditional or folk medicine is an oral tradition of health care prevalent amongst most tribal and rural communities in India and other parts of the world. It is a decentralised, autonomous and community supported institution based on local knowledge and resources. Even today, traditional 
medicine is known to cater to the health needs of large number of people in developing countries. However, the situation is rapidly changing as the Government-sponsored Western or "Allopathic" medicine is obliterating traditional medicine from tribal areas.

Political resolve to update the region and open it to outside world has altered social structure and demographic distribution resulting in erosion of traditional values and religious beliefs and practices. The goal of health for all by the year 2000 and the development of primary health care have led to increased interaction between the two systems. Tribal communities in Himalayan districts are in front of a related dilemma. Their own systems of health care are being replaced by state-sponsored hospitals; primary health centres; private dispensaries and so on. To dismiss traditional medical systems as ineffective or weak is to overlook their relevance and benefits in the contexts of their sociocultural systems. At the same the shortcomings of modern medical systems: their technical complexity, rising costs, curative rather than preventive focus, iatrogenic risks, and limited accessibility for large population sectors can not be overlooked. The government run health delivery system does not function properly and so tribal are forced to depend on private medical practitioners even for their basic health needs. Some private practitioners are not even formally qualified to prescribe or use allopathic medicines. Tribal do not have any option but to avail of the substandard medical services from private practitioners at exorbitant costs. Tribal are availing many and varied medicines; that exist alongside each other and intermix leading sometimes to hybrid form on the medical and social planes. Traditional health care practitioners, mobilise diverse chronicle so as to construct their present position. The therapists negotiate their social position in their community.

Western medicine, as a component of the grand imperial project, when introduced remained largely restricted to the enclaves of British political and cultural dominance such as the army, the prison, and the European settlement and had little effect on the overall health of India. In the last 50 years, despite penetration of biomedicine in remote areas, traditional ideas of disease and therapies prevail.

Resources and treatments from different medical and religious traditions are being utilised by the tribal population in the hills. The studies reveals how tribal cope with health, social, marital and other problems. The spiritual world of tribal culture exists as a means of coping with health problems. Traditional health culture has generally been accused of erecting barrier to the use of biomedicine and bifurcation between traditional and modern medical systems still obtains in the anthropological literature. It was believed by earlier authors that these two are discrete and biomedicine will replace traditional medical systems over time (Foster and Anderson, 1978). However, studies have established that in rural/ tribal India traditional medical practices as well as biomedicine co-exist. As traditional medical systems have survived here for such a long time, its therapeutic value and what is retainable of traditional systems and how these can be upgraded through education, licensing and incorporation in to state health becomes important. The state health programmes are well intended but lack anthropological consultation. To date, research into traditional medicine has been covered mainly by anthropology and it is suggested that other scientific disciplines should be incorporated in order to further rescue and revalue this part of the cultural heritage that has contributed substantially to human health and to the development of indigenous medical knowledge and its resources.

\section{REFERENCES}

Abu-Lughod, Lila. 1991. "Writing Against Culture" in Richard. G. Fox (ed.), Recapturing Anthropology: Working in the Present. School of American Research Press.

Ackerknecht E.H. 1943. "Psychopathology, primitive medicine and primitive culture." Bullettin of the History of Medicine, 14: 30-67.

Ackerknecht E.H. 1944. "Primitive Surgery." American Anthropologist, 49: 25-45.

Ackerknecht E. H. 1946. "Natural diseases and rational treatment in primitive medicine." Bullettin of the History of Medicine, 19(5): 467-497.

Adame, Vincanue. 1992. "Reconstituted relations of production in Sherpa Tourism." Ann. Tourism Research, 19.

Baer H.A., M. Singer and I. Susser. 1977. Medical anthropology and the World System. A Critical Perspective. Westport, London: Bergin and Garvey.

Bhasin, V. 1989. Ecology, Culture and Change: Tribals of Sikkim Himalayas. New Delhi: Inter India Publications.

Bhasin, V. 1990. Habitat, Habitation and Health. A Comparative Study of the Peoples of Sikkim and Gaddis of Himachal Pradesh. Delhi: Kamla-Raj Enterprises.

Bhasin V. 1997. "The human settlements and health 
status in Sikkim", (pp. 153-188) in K. C. Mahanta (ed.), People of the Himalayas. Delhi: Kamla-Raj Enterprises (1997).

Bhasin,V. 1997. "Medical Pluralism and Health Services in Ladakh." J. Hum. Ecol., 1: 43-69.

Bhasin, V. 1999. Tribals of Ladakh: Ecology, Human Settlements and Health. Delhi: Kamla-Raj Enterprises.

Bhasin, V. 2002. "Traditional Medicine Among Tribals of Rajasthan." J. Soc. Sci., 6(3): 153-172.

Bhasin, V. 2004a. "Sexual Illnesses and Underutilization of Biomedicine among Tribal Women of Rajasthan." Anthropologist, 6(1): 1-12.

Bhasin, V. 2004b. "Oral Health Behaviour Among Bhils of Rajasthan." J. Soc. Sci., 8(1): 1 - 5 .

Bhasin, V. 2005. Medical Anthropology: Tribals of Rajasthan. Delhi: Kamla-Raj Enterprises.

Bourdieu, P. 1990 The Logic of Practice. Great Britain:Cambridge Polity Press (1990).

Bourdieu, P. 1996. Distinction. A Social Crittque of the Judgement of Taste. Great Britain: Routledge (1986).

Brumann, Christoph. 1999. "Writing For Culture: Why a Successful Concept Should not be Discarded." Current Anthroplogy, (Supplement).

Caudill W. 1953. "Applied anthropology in medicine", in A. L. Kroeber (ed), Anthropology Today. Chicago: University of Chicago Press.

Charak Samhita, Sutra Sthana, Chapter 1, Shaloka 120121.

Clements F.E. 1932. "Primitive concepts of disease." University of California Publications in American Archaeology and Ethnology, 32(2): 185-252.

Cosminsky, S. 1977: "Impact of methods on the analysis of illness concept in a Guatemalan Community." Social Science Medicine, ll: 325.

Cunningham, K. 1989. "Cultural perceptions of disability" Uts'itishtana'i Newsletter of the American Indian Rehabilitation Research and Training Center.

Danforth, Loring M. 1989. Firewalking and Religious Healing. Princeton: Princeton University Press (1989).

Diasio N.1999. La science impure. Anthropologie et medicine en France, Grande-Bretagne, Italie, PaysBas. Paris: PUF An Analysis of Concepts of Pollution and Taboo.

Doshi, S.L. 1971. Bhils: Between Social Self-awareness and Cultural Synthesis. New Delhi: Sterling Publishers.

Douglas M. 1966. Purity and Danger. London: Routledge and K. Paul.

Edgerton, R.: 1980. "Traditional treatment for mental illness in Africa: A review." Culture, Medicine and Psychiatry, 4: 167-189.

Evans-Pritchard E.E. 1937. Witchcraft, Oracles and Magic among the Azande. Oxford: Claredon Press.

Fabrega, H. Jr. 1974. Disease and Social Behaviour: An Interdisciplinary Perspective. Cambridge, Mass: MIT Press.

Fadlalla, A. H. 2002. "Modest Women, Deceptive Jinn: Perception of Foreignness, Danger, and Disease Among the Hadendowa of Eastern Sudan ." HCPDS Working Paper Series, Volume 12 Number 6.

Foster, G.M. 1974. "Medical Anthropology: Some Contrasts with Medical Sociology." Med. Anthropol. Newsl., 6(1): 1-6.

Foster, G.M. and B. Anderson, B. 1978. Medical Anthropology. New York: Wiley.
Gevitz, N. 1988. Other Healers: Unorthodox Medicine in America. Baltimore: John Hopkins University Press.

Gonzales, N.S. 1966. "Health Behaviour in Cross-cultural Perspective: A Guatamalan example." Human Organization, 25: 122.

Groce, Nora Ellen. 1990. "Traditional Folk Belief Systems and Disabilities: An Important Factor in Policy Planning." One in Ten. NY: Rehabilitation International / UNICEF, 9: 2: 2-7.

Grollig, F.X. and H. B. Haley (Eds.) 1976. Medical Anthropology. The Hague: Mouton.

Hahn, Robert A. 1995. Sickness and Healing: An Anthropological Perspective. Yale University Press.

Janzen, John. 1978. The Quest for Therapy: Medical Pluralism in Lower Zaire. Berkely: University of California Press.

Johnson T.M. and C. F. Sargent (Eds.).1990. Medical Anthropology. A Handbook Of Theory and Method. New York, Westport, London: Greenwood Press.

Khare, S. 1996. "Dava, Daktar, and Dua: Anthropology of practiced medicine in India." Social Science Medicine, 43(5): 837-848.

Kimball, L.A. 1979. Borneo Medicine: The Healing Art of Indigenous Brunei Medicine. Ann Arbor: UMI Monogr. Publ.

Kleinman, A. 1978a. "Concepts and a model for the comparison of medical systems as cultural systems." Soc. Sci. Med. B 12: 85-93.

Kleinman, A. 1978b. "Clinical relevance of anthropological and cross-cultural research: concepts and strategies." Am. J. Psychiatry, 135: 427-431.

Kleinman, A. 1980. Patients and Healers in the Context of Culture: An Exploration of the Borderland Between Anthropology, Medicine and Psychiatry. Berkeley: University California Press.

Klienman, A 1981. "On illness meanings and clinical interpretation: not 'Rational Man', but a rational approach to Man the Sufferer/ Man the Healer." Cult. Med. Psychiatry, 5: 373-77.

Kleinman, A. and L. H. Sung. 1979. "Why do indigenous practitioners successfully heal?" Soc. Sci. Med., B 13: 7-26.

Kleinman, A. and T. Lin, T. (Eds.) 1982. Normal and Abnormal Behaviour in Chinese Culture. Dordecht, Holland: Reidel.

Lampe, Frederick (Fritz) P. 2003. "Creating a Second Storey Woman: Introduced Delineation Between Natural and Supernatural in Melanesia."(November 2003).

Landy, D. (Ed.) 1977. Culture, Disease and Healing: Studies in Medical Anthropology. New York: Macmillan.

Landy D. 1983. "Medical Anthropology: A critical appraisal", (1: 184-314) in J. Ruffini (ed.), Advances in Social Science. New York: Gordon and Breach.

Lebra, W.P. (Ed.) 1976. Culture Bound Syndromes, Ethnopsychiatry and Alternate Therapies. Honolulu: Univ. Hawaii Press.

Leslie, C. (Ed.) 1976. Asian Medical Systems: A Comparative Study. Berkely: Univ. Calif. Press.

Leslie, C. 1978. "Special issue on the theoretical foundationd for the comparative study of medical systems." Soc. Sci. Med., B12(2).

Leslie, C. 1980. "Special issue on medical pluralism." Soc. Sci. Med., B14(4) 
Lewis, G. 1975. Knowledge of Illness in a Sepik Society. London: Athlone.

Lindbladh, Eva and Carl Hampus Lyttkens. 2002. Habits versus choice: the process of decision- making in health-related behaviour. Social Science and Medicine, 55: 451-465.

Lindenbaum, S. 1979. Kuru Society: Disease and Danger in the New Guinae Highlands. Palo Alto, California: Mayfield.

Logan, M.H. and E. E. Hunt Jr. (Eds.) 1978. Health and the Human Condition: Perspective on Medical Anthropology. North Scituate, Mass: Duxbury.

Lohmann, Roger Ivar. 2003. "The Supernatural is Everywhere: Defining Qualities of Religion in Melanesia and Beyond."Anthropological Forum (November 2003).

Loudon, J. (Ed.). 1976. Social Anthropology and Medicine. London: Academic.

Manning, P. and H. J. Fabrega. 1973. "The experience of self and body: Health and illness in Chiapas highlands", (p. 290) in G. Psathas (ed.), Phenomenological Sociology. New York: Wiley.

McElroy A. and P. K. Townsend. 1979. Medical Anthropology in Ecological Perspective. North Scituate, Mass: Duxbury.

Neumann, A.K. et a1.1971. "Role of Indigenous Medicine Practioners in Two Areas of India: Report of a Study." Social Science and Medicine, 5: 13.

Ohnuki-Tierney, E. 1980. "Ainu illness and healing: a symbolic interpretation." Am. Ethnol., 7: 132-151.

Ortega, F. 1988. "Health systems and traditional medicine in Ecuador." Dev Sante, 78: 25-27.

McElroy, A. and P. K. Townsend. 1989. Medical Anthropology in Ecological Perspective. $2^{\text {nd }}$ edition. Boulder, san Francisco, London: Westview Press.

Moore, L.G., P. W. Van Arsdale, J. E. Glittenberg and R. A. Aldrich 1980. The Biocultural Basis of Health: Expanding Views of Medical Anthropology. St. Louis: Mosby.

Morley, P. and R. Wallis (Eds.). 1978. Culture and Curing: Anthropological Perspectives on Traditional Medical Beliefs and Practices. London: Owen.

Morsy, S.A. 1993. Gender Sickness and Healing in Rural Egypt. Ethnography in Historical Context. San Fransisco: Westview Press, Mueck, M.A.

Murdock, G.P. 1980. Theoties of Illness: A World Survey. Pittsburg: University Pittsburgh Press.

Ngubane, H. 1977. Body and Mind in Zulu Medicine: An Ethnography of Health and Disease in NyuswalaZulu Thought and Practice. New York: Academic.

Nichter, M. 1989. Anthropology and International Health: South Asian Case Studies. Dordrecht, Netherlands: Kluwer Press.

Nichter, M. (Ed.) 1992. Anthropological Approaches to the Study of Ethno-medicine. University of Arizona Tuscon: Gordon and Breach Science Publishers.
Nabokov, Isabella. 2000. Religion Against the Self. Oxford: Oxford University Press.

Pedersen, D. and V. Bariffati. 1989. "Healers, saints and doctors: Elements for the analysis of medical systems." Social Science Medicine, 29(4): 487-96.

Panzer, N.M. 1968. The Ocean of Story. Delhi: Motilal Banarsidas (Reprinted), Vol. 10 (1968).

Ramble, C. and C.P. Chapagain. Primary Notes on the Cultual Dimensions of Conservation. Report No. 10. Makalu-Brown Conservation Project Working Papers Publication Series. DNPWCAW.

Rivers W.H.R. 1924. Medicine, Magic and Religion. London: Kegan, Paul, Trench, Turner and Co.

Romanucci-Rock, L, Daniel E. Moreman and Laurence R. Tancredi (Eds.). 1997. The Anthropology of Medicine From Culture To Method. Connecticut: Bergin and Garvey.

Ruffini J. (Ed). 1983. Advances in Social Science. New York: Gordon and Breach.

Ryan, Gery. 1988. "What do sequential behavioural patterns suggest about the medical decisions making process?: Modeling home case management of acute illnesses in a rural Cameroon village." Social Science and Medicine, 46(2): 209-225.

Scheer, J and N. Gross. 1988. "Impairment as a Human Constant: Cross-Cultural and historical perspective on variation." Journal of Social Issues, 44(1): 23-37.

Susrutha Samhitha, Sutra Sthana, Chapter 36, Shaloka 10.

Turner, V.W. 1967. The Forest of Symbols: Aspects of Ndembu Rituals. Ithaca: Cornell University Press.

Turner, V.W. 1968. The Drums of Afflictions: A Study of Religious Processes among the Ndembu of Zambia. Oxford Claredon.

Van der Geest,S. and K. W. Van der Veen (Eds.). 1979. In Search of Health: Essays in Medical Anthropology. Amsterdam: Vakgroep Culturele Anthropologie et Nietwesterse Sociologie Algemeen, Univ. Amsterdam.

Virchow R. 1879. Gesammelte abhandunglen aus dem Gebeit der Oeffentlichen Medizin under Seuchenlehere. Berlin: Hirchwald.

Von Mering O. 1970. Medicine and Psychiatry. (pp. 272-307) in O. von Mering and L. Kasdan (eds.), Anthropology and the Behavioual and Health Sciences. Pittsburg: University of Pittsburg Press.

Wood, C.S. 1979. Human Sickness and Health: A Biocultural View. Palo Alto: Mayfield (1979).

Worseley P. 1982. "Non-western medical systems." Annual Review of Anthropology, 11: 315-348.

Young, J.C. 1981. Medical Choices in a Mexican Village. New Brunswick: Rutgers Univ. Press.

Young A. 1982. "The anthropologies of illness and sickness." Annual Review of Anthropology, 11: 257285 